\title{
PHENOMENON OF CAUSAL FRAUD HEALTH INSURANCE IN HOSPITALS: THEORY OF GEAR FRAUD
}

\author{
Haruddin Haruddin*, Dedi Purwana, Choirul Anwar \\ Jakarta State University, Indonesia
}

Correspondence: Joanne.Morris@canberra.edu.au

\section{ABSTRACT}

\section{OBJECTIVE}

To describe and explore the experiences of hospital employees with the causes of fraud in the health insurance program at the hospitals.

\section{DESIGN AND SETIING}

This research was carried out at government hospitals in the Southeast Sulawesi Province in collab oration with BPJS Health, namely the Bahteramas Regional General Hospital and the Kendari City Regional General Hospital. Triangulation was carried out at BPJS Health, the Center for Health Insurance Financing at the Ministry of Health and the Center for Health Policy and Management at Gadjah Mada University, Yogyakarta. This research was conducted for one year, namely January 2020 to February 2021 qualitative method with a phenomenological approach. Data collection methods were carried out through in-depth interviews, focus group discussions, and document studies. The number of participants in this study was 44 people consisting of doctors in charge of services, nurses, midwives, and case-mix team including coders who met the inclusion criteria. Data analysis used the Moustakas method.

\section{RESULT}

The causes of health insurance fraud in hospitals financial motives (the desire to get money or material or economic or welfare benefits, get high service services and low employee salaries), behavioral motives (low integrity, lifestyle and employee habits of committing fraud0, and social motives (kinship, humanitarian factors, avoiding conflict, social position, and the existence of pressure), internal controls (a weak monitoring system, poorly enforced regulations, unclear regulations and limited hospitals providing services, no monitoring and evaluation, and there are no sanctions for fraud perpetrators), revenue targets (hospitals income and increasing the number of claims), leadership (leadership style or weak leadership in the hospitals and the absence of transparency), incentive systems (poor distribution of incentives and the absence of transparency of services from hospitals management), National Health Insurance (NHI) regulations (dynamic regulations and the availability of the National Guidelines for Medical Services has not been fulfilled and there is no standard for readmission and fragmentation), the NHI financing system (inconvenience of the financing system and the adequacy of the INA-CBGs tariff calculation), and the BPJS Health system (inconvenience of the BPJS Health system and the BPJS Health system which makes it difficult).

\section{CONCLUSIONS}

The causes of health insurance fraud in hospitals can be explained by the gear fraud theory that Internal factors are the main cause and external factors predispose to health insurance fraud in hospitals. These internal and external factors 
interact with each other like the working mechanism of a gear. Understanding the theory of gear fraud will help formulate fraud prevention efforts in health insurance programs in hospitals that are more comprehensive and focus on eliminating the causes of fraud.

\section{KEYWORDS:}

Causes of fraud, health insurance, gear fraud theory

\section{INTRODUCTION}

The potential for fraud that may occur in mental hospitals includes efforts to extend or shorten the length of treatment (AvLOS), making fictitious bills for examinations and actions taken, and lodging patients for unclear indications. This is supported by the data obtained that there was a decrease in AVLOS during the implementation of the health insurance system with a payment system per diagnosis package but accompanied by an increase in the hospitalization rate by five times. This shows an indication that the potential for fraud affects the quality of outcomes for mental hospital patients.[1]

The National Health Insurance (NHI) program found the potential for fictitious claims of 175 thousand claims from hospitals with a loss value of around Rp. 400 billion during 2015 and increased to 1 million fictitious claims in 2016 valued at Rp. 1.9 trillion.[2]

Moral hazard and fraud still occur and have the potential to continue with the current policy environment. The findings show that the cause is the desire to increase the profit/profit and economic value of the Indonesia Case Base Group's (INA-CBGs) and capitation funds in the Health Insurance scheme.[3]

The potential for fraud in health insurance that can occur in hospitals of July 2016 is: coding errors as many as 528,285 cases $(49.77 \%)$, service unbundling or fragmentation as many as 265,572 cases $(25.02 \%$ ), phantom billing as many as 6,105 cases $(0.66 \%)$, phantom procedure as many as 7,221 cases $(0.68 \%)$, change in inpatient class as many as 37,714 cases $(3.55 \%)$, recurring bills as many as 12,025 cases (1.13\%), length of hospitalization as many as 2,266 cases $(0.21 \%)$, readmissions as many as 63,980 cases $(6.03 \%)$, services that did not benefit were 45,262 cases $(4.26 \%$ ), service cancellation but still billed as many as 35,659 cases (3.36\%), service standards as much as 32,013 cases $(3.02 \%)$, $20,705(1.95 \%)$ unnecessary therapy, 1,847 cases $(0.17 \%)$ excess bills, 1,072 cases $(0.1 \%)$ referral, 800 cases $(0.08 \%)$ cloning, fee contributions as many as 559 cases $(0.05 \%)$ and users Excess ventilator training in 331 cases $(0.03 \%)$. [4]

The variables of pressure, rationalization, and opportunity have a positive and significant effect on fraud prevention.[5] organizational commitment and leadership morality have a positive effect on the intention to commit fraud while the love of money, moral leadership, work environment, religious beliefs, and organizational culture have a negative effect on fraud. [6]

The novelty of this study is that the gear fraud theory is able to explain the factors that cause fraud in the health insurance program in hospitals more comprehensively, both internal and external factors.

\section{METHODS}

This research was carried out at government hospitals in the Southeast Sulawesi Province in collaboration with BPJS Health, namely the Bahteramas Regional General Hospital and the Kendari City Regional General Hospital. Triangulation was carried out at BPJS Health, the Center for Health Insurance Financing at the Ministry of Health and the Center for Health Policy and Management at Gadjah Mada University, Yogyakarta. This research was conducted for one year, namely January 2020 to February 2021. The research design used qualitative method with a phenomenological approach. The object of this research is fraud in the health insurance program at the hospital and the researchsubjects are Physicians in Charge of Services, Nurses, Midwives, Casemix Team including coders. The selection of participants with inclusion criteria has experience related to fraud in the health insurance program in hospitals and work in hospitals. The number of participants in this study was 44 participants including 4 participants as source triangulation, expert/researcher triangulation. Data collection was carried out through indepth interviews, focus groups discussion, and document studies. The data analysis technique in this study uses the 
Moustakas method. Ethics approval was not required for this study.

\section{RESULTS}

\section{FINANCIAL MOTIVE}

Financial motives include the desire to get money or material or economic or welfare benefits, get high service services, and low employee salaries. This is as expressed by the following participants:

"Can the welfare factor eh financial means money, financial, economic, welfare is felt to be lacking."(P17)

\section{BEHAVIORAL MOTIVE}

The behavioral motives that arise include low integrity, lifestyle, and employee habits of committing fraud. This is as expressed by the following participants:

"The first factor is the low integrity of the perpetrator. "(Pl)

"Talking about finances, we can't relate to saying the whole thing, because there are also financial people who are fulfilled, but because there are habitual factors and maybe finances are sufficient, but because their lifestyle is higher, deviant things can be done."(P!3)

\section{SOCIAL MOTIVE}

Social motives that arise include kinship, humanitarian factors, and avoiding conflict. This is as expressed by the following participants:

"In my personal experience, on average we commit fraud, maybe from a psychological point of view, so we want to help patients, especially families of people, meaning families of fellow officers, health workers like that."(P3D)

\footnotetext{
"A factor of avoiding conflictsuch as the case in the emergencyroom for fear of a conflict being accepted by the patient, but with that, it changes, then the human factor, why do I say humanity like that described by a friend, he helps to direct it so that it will be claimed later because he is his heart said they could not but humanity." (P1)
}

Some of the participants also revealed that other social motives for health insurance fraud in the hospitals were social position and the existence of pressure, as expressed by the following participants:

"There is a special appreciation for someone, so in the end fraud like that happens."(P3D)

"Then usually there is also pressure from the doctors in charge of services parties."(P16)

\section{INTERNAL CONTROL}

Poor internal controls include a weak monitoring system, poorly enforced regulations, unclear regulations, and limited hospitals providing services. This is as expressed by the following participants:

"Weak monitoring system like in case mix, for example, a diagnosis written by a doctor like this, but we replace it with another one so that for tariffs, to increase rates, that way."(PCMIB)

"Maybe the rules are not clear enough, the hospital's rules."(PCM5B)

"...the rules are not enforced." (PCM3B)

"The limitations of hospitals in providing pharmacies, uh yes, pharmacies continue to be with the same lab and support, that's finally the examination, even though it can take one day, sir, but two days and three days, repeating, even though one cycle, deliberately beheaded, cases 400 to 700."(PCM6B)

In addition, some participants revealed that poor internal control also means that there is no monitoring and evaluation, there is an opportunity for trial and error and there are no sanctions for fraud perpetrators, as expressed by the following participants:

"No monitoring, no evaluation."(P17)

"Cheating is done because there is an opportunity. Maybe the services are lacking. At first, maybe he was just trying it forfun, the joy was fun, yes it continues."

(P2) 


\section{LEADERSHIP}

"There is no enforcement of sanctions or punishment. There is no clear sanction for the perpetrator, it ends up happening continuously."(P1 1 )

\section{REVENUE TARGET}

The results showed that a hospital's income is one of the causes of health insurance fraud in hospitals from the aspect of hospital governance. The causes of hospital's income include increasing hospitals income and increasing the number of claims. This is as expressed by the following participants:

"of course he wants to increase income, nothing else, with the Diagnosis Related Group's (DRG), indeed, if the DRG adjustment, the rate from 2016 to the present, doesn't increase too much, so we say it's a tariff adjustment because some have increased, some have decreased indeed at that time and indeed in hospitals, especially private ones, maybe the margins might not be that big, maybe from that side of things, so you want or don't want them to play until they indicate upcoding, indicated double claims and so on, yes you don't want to yes they encourage their run towards income."(P3P)

Other participants revealed that the causes of hospital revenue that can lead to fraud include indirect management directives so that income is not minus and the hospital's income is low. This is as expressed by the following participants:

"Maybe there was direction from internal but not directly, actually we felt when we were presented that it was minus income, so we, that's why I started to finally think about how to make this plus, want to do several ways, for example speeding up patient hospitalization, the medicine is given at a minimum so that it is more, more profitable. Maybe that is what is meant, but that was not a direct direction, right, like that."(P3D)

"Internal factors can also be included, especially if for example the hospital has low income. So the manager tries how to make the hospitals' income increase."(P2D)
Leadership factors include leadership style or weak leadership in the hospitals and the absence of transparency, as revealed by the following participants:

"Leadership style or weak leadership, it can have a huge impact, on all the staff involved, in their field to carry out their duties."(PCM8B)

"The factormay also be that there is no transparency from the management so that people are competing how to make a profit, how to improve their welfare and also Internal Control Unit frankly I have been visited by the internal control unit, I am honest about why they want to find out why this doctor he was a fraud, Internal Control Unit already knew he was a fraud, the doctor but until now there has been no action from Internal Control Unit or the management for the doctor, instead I am the head of the room who is hated, because why I gave information. There was no enforcement of sanctions or punishments."(P2)

\section{INCENTIVE SYSTEM}

Incentive systems include poor distribution of incentives and the absence of transparency of services from hospital management. This is as expressed by the following participants:

\begin{abstract}
"Because the distribution of the service system is not good, it is not transparent, we continue to provide services with a conscience. But what about our optimal service, which is minimal."(P15)
\end{abstract}

"Then in the distribution of the incentives it is lacking, it is not enough for them."(P4)

"Lack of transparency on the part of management in terms of service sharing." (P5)

"Then also nobody cares about it, we also do not affect us, we still receive that kind of service, it's the same."(P3D)

\section{NATIONAL HEALTH INSURANCE REGULATIONS}

Health insurance regulations include dynamic regulations and the availability of the National Guidelines for Medical Services has not been fulfilled and there is no standard for 
readmission and fragmentation, as disclosed by the following participants:

"The first is the regulation that has just been running, we just started the NHI program in 2014, now along with that, if you pay attention to it, there are a lot of very dynamic regulations meaning that they are still changing and looking for patterns and if this is linked With the fraud theory itself, one of the fraud theory is that there is an opportunity when there are gaps in the regulations that are still rolling and the changes are still dynamic, it can be an opportunity for each party to commit fraud motives." (P2P)

"Maybe in Indonesia itself, the National Guidelines for Medical Services is not entirely available for all fields, whether in the medical field or the medical field, and maybe what I know is that the update until now has not reached there are 10 maybe more or maybe, but not all of these are one thing, meaning they have not been fulfilled. availability of the National Guidelines for Medical Services which applies nationally."(P2P)

"There is no standard of readmission and fragmentation."(P3P)

\section{NATIONAL HEALTH INSURANCE FINANCING SYSTEM}

The health insurance financing system includes the inconvenience of the financing system and the adequacy of the INA-CBGs tariff calculation, as disclosed by the following participants:

"Because this funding has just been carried out in this program, so maybe many of them still haven't quickly adjusted what the financing pattern is. that given will certainly be the initial point of view for service providers to see the enactment of such regulations on health insurance financing." $(P 2 P)$

"Yes, because from the INA-CBGs concept, the tariff calculation is indeed from the average side, yes, we calculate it. Out layer has an inlayer, there is an above that is below the line right? because the average is drawn, now for cases that are below the average that is below the average, the chances of that diagnosis or procedure will usually be done by the hospitals later, so indeed one of the factors could be due to sufficient because from the best average. That's in terms of calculating the rate."(P3P)

\section{THE BPJS HEALTH SYSTEM}

The BPJS Health system includes the inconvenience of the BPJS Health system and the BPJS Health system which makes it difficult, as stated by the following participants:

"The BPJS Health system that he must self-examine. The existing system in the BPJS Health is too difficult, sometimes because there are several criteria that we must meet to be able to claim a diagnosis." (P6)

"The second is the discomfort with the BPJS Health system, they are not comfortable with the BPJS Health which is like a superpower." (PIP)

\section{DISCUSSION}

This study showed that personal motives are a cause of health insurance fraud in hospitals. Personal motives consist of financial motives, behavioral motives, and social motives. Financial motives include the desire to get money or material or economic or welfare benefits, get high service services, and low employee salaries. Financial motive is the main motive for fraud, although fraud requires the presence of other factors such as opportunity and justification for the fraud committed by the perpetrator. Financial pressures experienced by employees to make ends meet encourage people to look for other ways to resolve these financial pressures. Low salaries and services received are one of the causes of fraud in hospital health insurance. The fraud triangle defines three elements that exist in every fraud situation. These three elements must be existed for fraud to occur. If one element is omitted, fraud will not be committed or will be prevented by the organization's internal control. The three elements are motive, rationalization, and attitude.[7] In general most of the participants felt that fraudsters showed an extraordinary urge to be successful and rich.[8] In almost every case, health care fraud focuses on money.[9] the potential for fraud Hospitals can occur because of pressure, opportunity, and rationalization. The pressure factor is caused by the high unmet needs and the low salary received.[10]

The behavioral motive that arises include low integrity, lifestyle and employee habits of committing fraud. Behavior is one of the factors that influence the occurrence 
of fraud. Behavior is an action or action carried out by a person or group of people based on personal values that are believed and if the behavior is carried out continuously it will form a pattern of behavior in acting. Behavior is also a manifestation of the thoughts and feelings experienced by a person or group in response to a stimulus in that person or group. Dishonest behavior and hedonism will encourage people to commit fraud. At the health service level in the hospitals, employees who behave dishonestly and unethically will easily commit fraud, and behavior like this will also tend to be repeated. A theory rooted in psychology is based on the view that criminal behavior is a product of mental processes.[11] the sociology and criminology literature describes fraud perpetrators as "trust violators" in other words, trust violators are people who are usually not suspected of committing fraud.[12] In particular, belief-breakers and fraudsters must be able to justify their actions against themselves and others as a psychological coping mechanism for dealing with the inevitable "cognitive dissonance," a lack of conformity between their perceptions of honesty and the deceptive nature of their actions or behavior.[12] Furthermore, that personal incentives and perceived pressure drive human behavior, and the need to rationalize wrongdoing as something that can be psychologically defended is deeply rooted in the notion of cognitive dissonance.[12]

The social motive that arises includes kinship, humanitarian factors, avoiding conflict, social position, and the existence of pressure. Social motives are extrinsic motives that a person has to behave by social demands. This social motive presence can contribute to the incidence of health insurance fraud in hospitals. The pattern of kinship relationships and the nature of wanting help to ease the burden on family members or community members in social kinship clumps trigger Health insurance fraud in hospitals. The use of other people's health insurance cards by patients and is assisted by the involvement of internal hospital parties because of kinship factors or because of a sense of social humanity further adds to the vulnerability of health insurance fraud in hospitals. In the social structure, it is also known as the social strata, which this phenomenon still exists until now, especially those who have a position or position in the government, usually will get priorityin getting health services even though procedurally there are things that must be violated. Besides that, the superior position of a certain person sometimes makes people in a lower position silent to avoid conflict and allow fraud to occur even though they knowingly know that what is being done is fraud. Six motivational factors that encourage employees and managers to engage in fraudulent behavior are business financial pressure, incentives and social pressure, greed, operational problems, internal pressure, and a working environment. evil. In addition, fraudsters rationalized their behavior through five significant neutralization techniques which were identified as social weighting, error switching, injury denial, attitude, and previous history of fraud.[13] All justifying collusion is a central element in many complex and expensive fraud and white-collar crimes.[1 1 ]

This study showed that hospital governance can because of health insurance fraud in hospitals. The hospital governance internal control, revenue target, leadership, and incentive system. Hospital governance is a fundamental thing in good hospital management. Internal control includes a weak monitoring system, poorly enforced regulations, unclear regulations and limited hospitals providing services, no monitoring, and evaluation, and there are no sanctions for fraud perpetrators. Internal control is an internal system developed by the organization so that business processes are carried out effectively, efficiently, economically with high compliance with existing regulations. Internal control is very important for hospitals to minimize fraud in health insurance services. The better the internal control system built by the hospital, the more it will be able to identify, detect and prevent fraud. The current phenomenon associated with this internal control system is that many hospitals consider that the internal control system is only a document formalization process to complete the parameters of good hospital governance so that the hospitals turn into a "document storage warehouse" because the documents have very minimal implementation. The internal control system is not only the availability of the infrastructure for policy documents, guidelines, standards, fixed procedures, and others but the most important thing is the implementation of the entire internal control system infrastructure. The complete infrastructure of the internal control system, especially to prevent fraud in hospital's health insurance, will be meaningless if the entire infrastructure system is not functioning optimally. Organizations as victims of fraud are identified as having three main opportunities for fraud, namely poor control environment, inadequate control activity, and circumstances that allow collusive behavior among fraud perpetrators.[13]

The revenue target includes increasing the hospital's income and increasing the number of claims. In the current context of hospital management where hospital 
management implements the financial pattern of the Public Service Agency, hospital revenues are important to ensure the continuity of hospital operations. The current era of National Health Insurance with a payment system that is implemented with a prospective payment requires hospitals to apply the principle of service efficiency while maintaining the quality of services provided. The Indonesia Case Base Group's (INA CBGs) system that is used to pay hospitals claims bills also affects hospital's revenues. The slow payment of claims by BPJS Health is also a factor affecting the cash flow from the hospital's revenues. The importance of high income of hospitals meets operational needs and also the investment costs of medical devices can be a driving force for health insurance fraud in hospitals. The setting of high-income targets by the hospitals will force the hospitals to look for various ways to achieve this income target. One of them is trying to find loopholes in the system of health insurance.

Leadership factors include leadership style or weak leadership in the hospitals and the absence of transparency. Leadership is a person's ability to influence others in the form of words or actions. In the context of organizational management, leadership is the ability to move the resources owned by the organization in achieving goals. Every leader has a different leadership style even though scientifically the leadership style has been grouped by experts into several leadership style groups. In the context of health insurance fraud in hospitals, the leadership factor is one of the causes of fraud. The role of leadership in hospitals is very important to prevent health insurance fraud. A strong commitment accompanied by concrete actions taken by the leader is a real portrait that will become an example for employees in building antifraud attitudes and actions. Leadership that is weak and tends to be tolerant of acts of fraud will nurture fraud in the organization. To build a work environment in an anti-fraud hospital, the role of the leader is as a command in efforts to prevent fraud. Organizational justice, internal control systems, organizational commitment, and leadership style affect fraud. [14] Organizational commitment and leadership morality have a positive effect on the intention to commit fraud.[6]

Incentive systems include poor distribution of incentives and the absence of transparency of services from hospital management. The incentive is a type of compensation received by employees in the form of money as a reward for performance. Good and fair incentives will increase employee motivation to achieve the best performance.
Incentives in hospitals are given in the form of remuneration for hospitals that apply the financial pattern of the Public Service Agency and hospitals that are not Public Service Agency will provide incentives in the form of services. This incentive system must be established by considering the hospital's income, corporate grade, performance targets, and achievements so that employees are satisfied with the work incentives received. The determination of the number of incentives must also be communicated to employees including the formula used so that the openness and objectivity of performance measurement and the incentives received can be understood by all hospital employees. Lack of transparency and employee involvement in developing an incentive system will affect the working climate in the hospital. Rewards for performance are not good if the process of building a fair and objective incentive system is not carried out transparently. This will encourage fraud in health insurance in hospitals. Fraud among clinicians may be due to an imbalance between the health care system and the burden, service providers do not provide adequate incentives, inadequate supply of medical devices, system inefficiency, lack of transparency of health facilities, and cultural factors.[15]

This study showed that there are external factors that contribute to health insurance fraud in hospitals, namely health insurance regulations, health insurance financing system, and the BPJS Health system. Health insurance regulations include dynamic regulations and the availability of the National Guidelines for Medical Services has not been fulfilled and there is no standard for readmission and fragmentation. Regulation has an important role in the management of organizations and systems because it will provide order. Regulation is a set of rules or policies established by the regulator as a common guide that all elements related to the regulation must comply with. There are quite a lot of stakeholders in the $\mathrm{NH}$ program, starting from the central government, local governments, BPJS Health, the community, the business world, and health service facilities. Therefore, the presence of the government as a regulator has an important role in formulating regulations that will guide all stakeholders in carrying out their roles following existing regulations. Unclear or lack of regulation will encourage irregularity in the implementation of the NHI program and have the opportunity to increase the risk of fraud in hospital health insurance. There are still many problems in the implementation of $\mathrm{NHI}$, especially in the early stages of implementation. Problems related to policy and 
institutional aspects, program transformation, advocacy and socialization of the $\mathrm{NHI}$ program, membership, service infrastructure at health facilities, referral systems, and Human Resources and Capacity Building, aspects of financing, risks of fraud in the implementation of $\mathrm{NHI}$, and the impact of $\mathrm{NHI}$ on utilization, participant and provider satisfaction.[16]

The health insurance financing system includes the inconvenience of the financing system and the adequacy of the INA-CBGs tariff calculation. Health Financing is one of the important sub-systems in the National Health System and plays an important role in improving the management of the health service system in Indonesia. The health financing sub-system is the management of various efforts to control, allocate and spend health funds to support the implementation of health development to achieve the highest public health degree. The principles of the health financing sub-system are adequacy, effectiveness and efficiency, fairness, and transparency. The "inconvenience" in the health system causes various parties to make efforts to "save themselves" to survive while participating in the $\mathrm{NHI}$ program.[2] It is further argued that the INA CBG's rates are considered low by clinicians and the high workload makes them think about unnatural efforts to defend themselves so as not to lose money. To make matters worse, these clinicians sometimes share their "experiences" to "save themselves". They then apply these experiences in providing health services so that it becomes a culture. The basis for setting tariffs is also still mysterious for most groups, causing dissatisfaction with the system.[2]

The BPJS Health system includes the inconvenience of the BPJS Health system and the BPJS Health system which makes it difficult. As the provider of health insurance, BPJS Health is required to build and develop a good system with health service providers so that an equal partnership system is built between partners and BPJS Health. Moreover, based on the authority possessed by BPJS Health in terms of payments to health facilities which refer to government tariff setting and also making or terminating cooperation contracts with health facilities, make BPJS Health position as if it is above health service facilities. This condition creates discomfort in the relationship between the health insurance system. The non-uniform implementation of BPJS Health policies in the field makes health facilities seem "frustrated" with the existing system. Clinicians are required to comply with administrative procedures so that medical actions can be paid for by BPJS Health. So that in the field sometimes they have to be faced with conditions of "administrative manipulation" to meet the standards for filing claims and tend to sacrifice scientific autonomy and independence of clinicians.

The limitations of this study include, among others, that it was only conducted at two government hospitals, so further research is needed with a larger number of hospitals. In addition, the measurement of the influence of each variable causing health insurance fraud in hospitals has not been carried out in this study. The implications of this research for hospitals and policymakers are to become the basis for implementing improvements to the fraud prevention system in hospitals and for researchers to be the basis for future research in the science of health insurance fraud.

\section{CONCLUSION}

Gear Fraud theory is a new theory that was born to explain the causes of health insurance fraud in hospitals. This theory explains that there are two main factors causing health insurance fraud in hospitals, namely internal factors in the hospitals and external factors. Internal factors consist of employee personal motives and hospital governance. Employee personal motives consist of financial motives, behavioral motives, and social motives while hospital governance consists of internal control, revenue targets, leadership, and an incentive system. External factors consist of health insurance regulations, health insurance financing systems, and the BPJS Health system. Internal factors are the main cause and external factors predispose to health insurance fraud in hospitals. These internal and external factors also interact with each other, such as the working mechanism of a gear.

Understanding the theory of gear fraud will help formulate fraud prevention efforts in health insurance programs in hospitals that are more comprehensive and focus on eliminating the causes of fraud.

\section{References}

1. Ika, N. (2014). National Health on Service Quality. 03(04), 183-191. https://doi.org/https://doi.org/10.22146/ikki.36385

2. Djasri, H., Rahma, P. A., \& Hasri, E. T. (2016). Corruption in Health Services in the Era of National Health 
Insurance: A Study of the Potential and Fraud Control System. Integritas, 2(1), 113-133.

https://acch.kpk.go.id/id/component/content/article ?id=672 (accessed 26/7/2019)

3. Lauranti, M., Afrina, E., Mawesti, D., Nurrahamah, B., Muntafa, F., \& Suriyanto, F. (2017). National Health Insurance Contribution Assistance: Health Equity for the Poor and Near-Poor in Indonesia. (accessed 27/4/19)

4. GATRA. (2017). Potential Fraud in the JKN System. http://arsip.gatra.com/2017-0424/majal ah/artikel.php?pil=23\&id=164246 (accessed 29/9/19)

5. Kartini. (2018). Developing fraud prevention model in a regional public hospital in West Sulawesi Province. International Journal of Law and Management, 60(2), 210-220. https://doi.org/10.1108/IJLMA-04-2017-0095

6. Wicaksono, A. P., \& Urumsah, D. (2017). Factors Influencing Employees To Commit Fraud in Workplace Empirical Study in Indonesian Hospitals. Asia Pacific Fraud Journal, 1 (1), 1. https://doi.org/10.21532/apfi.001.16.01.01.01

7. Cendrowski, H., Martin, J. P., \& Petro, L. W. (2015). The Handbook of Fraud Deterrence. In The Handbook of Fraud Deterrence. Wiley. https://doi.org/10.1002/9781119202165

8. Sandhu, N. (2016). Behavioral Red Flags of Fraud - A Qualitative Assessment. Journal of Human Values, 22(3), 221-237. https://doi.org/10.1177/0971685816650579

9. Dietz, J., Bryan Gamble, W., Marchlowska, J., \& Wheeler, B. T. (2013). Fighting health care fraud in bold and innovative ways. Military Medicine, 178(10). https://doi.org/10.7205/MILMED-D-13-00205

10. Sadikin, H., \& Adisasmito, W. (2016). Analysis of the Influence of Fraud Triangle Dimensions in Fraud Prevention Policies on the National Health Insurance Program at Cipto Mangunkusumo National Hospital. Indonesia Health Economic Journal, 1 (2). https://doi.org/10.7454/eki.v1i2.1871

11. Vousinas, G. L. (2018). Elaborating on the theory of fraud. New theoretical extensions. 1-18.

https://papers.ssrn.com/sol3/papers.cfm?abstract id= $\underline{3163337}$

12. Ramamoorti, S. (2008). The Psychology and Sociology of Fraud: Integrating the Behavioral Sciences

Component into Fraud and Forensic Accounting
Curricula. Issues in Accounting Education, 23(4), 521 533. https://doi.org/10.2308/iace.2008.23.4.521

13. Zuberi, O., \& Mzenzi, S. I. (2019). Analysis of employee and management fraud in Tanzania. Journal of Financial Crime, 26(2). https://doi.org/10.1 108/JFC-012018-0012

14. Sumbayak, J. S. (2017). the Effect of Organizational Justice, Internal Control System, Organizational Commitment and Leadership Style on Fraud (Empirical Study at the Main Branch Office of a Leasing Company in Pekanbaru City). Online Journal of Students of the Faculty of Economics, University of Riau, 4(1).

15. Pustika Sukma, D., Sulistiyono, A., \& Tresno Novianto, W. (2018). Fraud in Healthcare Service. SHS Web of Conferences, 54, 03015. https://doi.org/10.1051/shsconf/20185403015

16. Maidin, A., \& Palutturi, S. (2016). Study on the Implementation of Cross-Provincial National Health Insurance (South Sulawesi, Southeast Sulawesi, West Sulawesi) 2014. Indonesian Journal of Health Policy, 05(03), 96-100.

https://drive.google.com/file/d/0Bzt046lJwcDTHp5dTh5RiFWNFF2RDNfbVItZ3hNMil aVFVi/view (accessed 7/3/20) 